\title{
A DESCONSTRUÇÃO DO EU: A ZERLEGUNG DE FREUD E A AUSLEGUNG DE HEIDEGGER
}

Ernildo Stein*

SINTESE - Desenvolve-se neste ensaio a primeira etapa do exame da teoria do eu em Freud como decomposição (Zerlegung) da personalidade psiquica na perspectiva da analitica existencial. PALAVRAS-CHAVE - Psicanálise. Eu. Desconstrução. Analítica existencial.
ABSTRACT - This paper develops the first part of one analysis in progress of Freud's theory of self as decomposition (Zerlegung) of the psychic personality in the existential-analytic's point of view.

KEY WORDS - Psychoanalysis. Self. Deconstruction. Existential analytics.

A questão do eu na psicanálise foi tratada pela maioria dos autores como se fosse um ponto de referência, entre outros, para a discussão do inconsciente e das diversas teorias desenvolvidas em torno dos chamados conceitos fundamentais da psicanálise.

Freud trata do eu como o conceito central de seu edifício teórico. Aliás, não faria sentido algum discutir questões do inconsciente sem a análise das implicações que isso tem para a concepção do eu como tal. Não há eu, consciência de si, consciente, identidade pessoal que mudariam de sentido e importância, conforme teorias relativas a eles, abordando novos aspectos do psiquismo humano. Certamente, houve progressos na filosofia no que se refere às teorias do eu, da identidade pessoal, do mesmo (Selbst), mas a posição central do eu não foi suprimida. Assim também nenhuma nova hipótese sobre o inconsciente irá legitimar-se se quiser substituir o eu por qualquer coisa mais importante. Haverá novas teorias do eu, mas o eu continua o mesmo como identidade central do ser humano consciente.

Podemos, no entanto, fazer desconstruções do conceito de eu levados por novas descobertas. É isso que aconteceu na psicanálise. Por isso, podemos perguntar pela desconstrução do eu como conceito na teoria freudiana. Sustenta-se a concepção clássica de eu depois da metapsicologia? Qual a consistência do conceito de eu na teoria freudiana? Muda com as hipóteses da psicanálise a concepção do eu como Freud o queria?

* Professor de Filosofia no Curso de Pós-Graduação em Filosofia da PUCRS.

\begin{tabular}{|l|l|l|l|l|l|}
\hline VERITAS & Porto Alegre & v. 44 & n. 1 & Março 1999 & p. 61-76 \\
\hline
\end{tabular}


Sigo esta problemmática em quatro etapas: a) a desmontagem (decomposição) do eu como personalidade psíquica em Freud, seu alcance, seus limites e as aporias trazidas pela psicanálise; b) o recurso à analítica existencial pode ajudar-nos a testar a poșição de Freud, desenvolvida em diversas etapas, na sua teoria como tal e especificamente na metapsicologia? c) qual o caminho que segue Heidegger em Ser e tempo para realizar a desconstrução do eu, da mesmidade e da consciẹncia e o que nos oferece o filósofo como conseqüência da analítica existencial; d) qual seria o perfil que poderia ser traçado da concepção de uma metapsicologia que passassse pelas diversas etapas de revisão à luz da concepção do Dasein de Heidegger?

No presente trabalho pretende-se apresentar um exame da desconstrução freudiana do eu e algumas referências à analitica-existencial do ponto de vista crítico.

A impressão que temos quando examinamos o edifício teórico de Freud e as etapas que levaram para a constituição do que ele passaria a chamar de psicanálise, não podemos dizer que se trata apenas da obra de um homem genial que de repente descobriu as bases de uma nova ciência. $O$ que podemos afirmar é que as diferentes frentes de seu experimentalismo e o leque de leituras psiquiátricas e psicopatológicas puseram-no em contato com uma soma de fatos que tinham diversas ligações entre si, mas que não recebiam de nenhum estudioso da época uma interpretação articulada, levaram-no a uma espécie de ensaio de tentativa e erro desenvolvido nos primeiros vinte anos de seu trabalho.

Até agora a quase totalidade dos intérpretes de Freud procurou encontrar um fio que unisse os múltiplos textos produzidos por um autor altamente dotado de capacidade literária. São, no entanto, múltiplas e recorrentes as referências de Freud a situações sem saída em seus escritos e a novas tentativas para ver se acertava aquilo que obscuramente se ia construindo na imaginação. É assim que a psicanálise toma forma através de uma soma de ensaios avulsos onde aparecem certos livros articulados numa unidade teórica parcial, mas não no todo da psicanálise.

Não é um bom caminho forçar, a partir de hoje, para dentro do edifício da obra de Freud uma doutrina unitária e um pensamento conseqüente e lógico. 0 que efetivamente aconteceu resultou do encontro de três aspectos da atividade de Freud: a) sua formação culturạl clássica em literatura, filosofia e antropologia; b) os conhecimentos psicológicos, médicos, psicopatológicos e biológicos; c) o conjunto de experiências clínicas, realizadas por ele e alguns de seus interlocutores, e o material delas surgido como novo e esperando interpretação. O trabalho da psicanálise constituiu-se, por isso, num ir e vir entre as diferentes interpretações dos fenômenos ainda não unificados sob o nome de uma ciência. O autor, quando fala em abandonar um tipo de conhecimento para se ocupar com outro, não recusa as informações anteriores acumuladas. É como se tivesse que retomar um objeto invisivel de análise através de um outro ângulo. Isso fąz, da psicanálise que surgiu de sua atividade, um edifício autobiográfico, ensaístico, por vezes tẹórico e muitas vezes de caráter especulativo ou filosófico. 
O que deu unidade à psicanálise em seus primeiros vinte anos foi o exercício de uma clínica, de uma nova prática de atendimento e interpretação dọ pacientes. De uma mudança de atitude diante dos sintọmas e com isso a introdụção de uma nova semiologia. Poucos psicanalistas que se tornaram os primeiros discípulos de Freud foram admitidos como participantes de uma espécie de grupo de pesquisa. Mas muitos, ou quase todos, foram confidentes e possuidores de informações resultantes de práticas clínicas. Era como se a multiplicação dos núcleos clínicos e estudiosos de casuística constituísșem a pșicanálise, reșervando-se Freud, não apenas o privilégio, mas a quase exclusividade de incorporar, no conhecimento psicanalítico, materiais teóricos e clínicos de seus colegas e discípulos. Mesmo que recusạsse certas interpretações teóricas de outros, Freud trabalhava, muitas vezes em segredo, sobre materiais alheios. É por isso que não temos propriamente vários fundadores da psicanálise. Freud tem a consciência e assume a pretensão de ser o fundador.

Esta é a razão por que o pensamento pșicanalítico se apresenta, nos primeiros trinta anos, como tendo sempre a autoria central de Freud. Somente no XIII Encontro Internacional de Psicanálise de 1934, em Lucerna, na Suíça, começam a aparecer contribuições, comunicações, conferências e debates de muitoș países, mas já não mais simplesmente no contexto do paradigma freudiano. Basta olharmos para algumas figuras que participaram desse Congresso sob a presidência de Ernest Jones: Anna Freud, Melanie Klein, Marie Bonaparte, L. Binswanger, W. Reich, Pfister, Ettingon e muitos outros. Apesar do cordão umbelical que os ligava a Freud ausente, muitos deles já șituavam suas contribuições ligadas a experiências clínicas, em contextos paradigmáticos bem diferentes das influências e conviç̧öes que cercavam Freud no nascimento da psicanálise. É por isso que podemos dizer que o encontro de 1934 constitui o começo da diáspora, geograficamente mas, sobretudo, teoricamente.

Ainda que tivessem sido ponderações de ordem política que modelaram o perfil do Congresso de 1934, Freud já se dera conta de uma diáspora da psicanálise que se constituíra pela recepçăo de suas idéias centrais e da prática em outros contextos históricos, culturais e paradigmáticos. Boa parte da obra de Freud, do fim dos anos 20 e dos anos 30 se constitui de análișes da inserção da psicanálise num universo cultural que, muito por causa da própria psicanálise, também estava sofrendo transformações profundas e ao mesmo tempo exigia novos modelos de interpretação. É assim que o destino da psicanálise se fazia mais dependente da obra de Freud e de sua interpretação, quanto mais a diáspora de seus adeptos trazia o risco da deformação das idéias psicanalíticas em outros contextos cultúurais e paradigmáticos.

Representa uma coincidência que a psicanálise tenhạ surgido no começo do século 20, quando se dava o início da desintegração da imagem do mundo predominante, centrada na concepção dos grandes indivíduos, das personalidades fortes e nạ concepção de um sujeito e de um eu autônomos. Não estaremos forçando demasiadamente a obra de Freud se dissermos que ela constitui, do ponto de vista 
cultural, uma nova reflexão sobre o eu, do ponto de vista psicopatológico uma nova interpretação das doenças do eu, do ponto de vista teórico uma reestruturação dos problemas do eu e do ponto de vista clínico uma nova experiência com uma nova dinâmica dos sintomas do eu. Se as descobertas de Freud do ponto de vista clínico e teórico constituem resultado de sua pesquisa aparentemente realizada em várias frentes, o elemento comum que constitui a preocupação do fundador da psicanálise é a questão do eu. A nova ciência causa escândalo, de um lado, porque amplia as estruturas que compõem o pretendido núcleo da personalidade humana e, de outro lado, porque revelam um quadro psicopatológico em torno do eu que o tiravam de seu centro. É assim que podemos ler, na sucessão dos textos da psicanálise, um duplo cuidado de seu fundador: mostrar os revolucionários aspectos da economia psíquica e da dinâmica interna do ser humano, eu quase diria europeu, e contudo preservar, através de uma tópica, ainda o papel central do eu diante dos processos inconscientes.

As descobertas de Freud representavam um destronamento das teorias do eu das psicologias nascentes e das diversas tendências psiquiátricas. Ainda que continuasse convencido do papel central do eu para os estudos que realizava, ele sabia que, ao transformar sua psicologia em metapsicologia, o eu nunca mais recuperaria o lugar que o século XIX lhe reservara, sobretudo nas teorias da subjetividade e no pensamento idealista. A interpretação das doenças mentais e a psicologia nascente da segunda metade do século XIX ainda se centravam em elementos empíricos ou teorias que pouco atingiam as questões do eu. Somente em alguns filósofos do final do século XIX e alguns estudiosos de psicopatologia haviam começado distinções no eu e divisões internas que apontavam para os conflitos da personalidade humana. Mas somente Freud conseguiu ser sensivel a essas diversas idéias procurando, no entanto, concretizá-las em hipóteses e pesquisas empíricas. Ainda que suas teorias novas com relação ao eu e a seus conflitos continuassem a se desenvolver e transformar progressivamente, era na clínica e na casuística psiquiátrica que se iam confirmando novos modos de abordar 0 problema do eu. Assim, a psicanálise começará a fazer uma nova leitura dos sintomas e a introduzir a teoria do recalcamento, ainda por iniciativa do eu, juntando a isso a massa de informações de vários especialistas em psicopatologia sobre o papel da sexualidade.

Não é sem razão que Freud terá problemas em manter constantemente separadas as etiologias das diversas neuroses, das patologias do eu. O problema do narcisismo é tão central na psicanálise desde o começo dos anos 10, não simplesmente porque aí se constituía um campo de investigação a mais, mas porque uma teoria do narcisismo iria atingir profundamente a concepção do eu. E nesse caso era necessário proceder com extrema cautela o que ainda revela a primeira tópica. Penso que somente a partir das novas descobertas de Freud em Para além do princípio do prazer lhe vem argumentos para ousar falar da decomposição do eu. Somente aí onde ações prejudicadas em sua liberdade pela compulsão não mais buscam ganhos para um aparente eu é que Freud pensa ter argumentos para destronar o eu de seu lugar único e situá-lo, no contexto da segunda tópica, ao lado do isso e do super eu. 
Para afirmar essa nova teoria do eu como parceiro de outras instâncias, Freud, no entanto, vê-se compelido a construir uma nova psicologia, uma nova concepção do eu, pela metapsicologia, concebida como um grandioso drama evolutivo em que se conjugam etapas da filogênese com o aparecimento das neuroses de transferência. Assim ainda que diminuído quanto ao lugar que ocupara no século passado, o eu torna-se palco em que se desenvolve o grande cenário metapsicológico das neuroses de transferência. Há, portanto, para Freud uma história evolutiva que justifica seu ataque frontal ao núcleo do psiquismo humano até aquele momento: o eu. Assim, a metapsicologia aparece com duas funções que conflitam entre si: ela possui um lado especulativo, quase filosófico, que Freud quer sistematizar nos doze trabalhos intitulados Preliminares para uma metapsicologia, parte dos quais é destruída por ter um caráter especulativo exagerado e que tinha a função de proteger a psicanálise contra as psicologias correntes, enquanto a outra parte é preservada porque se incorpora na outra função da metapsicologia que é confirmada na prática clínica e que, portanto, teria um caráter mais científico.

Ao querermos realizar uma crítica da psicanálise temos que levar em consideração o panorama até aqui traçado e observar em que horizonte paradigmático Freud tentou salvar o eu, apesar das novas evidências de suas descobertas e, por outro lado, criticar as teorias do eu porque deficientes ou inteiramente errôneas. A psicanálise tornou-se, certamente, um grande processo desconstrutivo do eu. $\mathrm{O}$ que temos a nos perguntar, nas análises que fazemos da obra freudiana, do ponto de vista de sua consistência, é tentar descobrir o melhor modo de compreender o seu trabalho de desconstrução, aceitando-o em seus resultados ou recusando-o porque ele teria operado com pressupostos paradigmáticos insuficientes, cientificistas, mecanicistas ou biologistas. Somente assim se poderão apresentar propostas que corrijam a desconstrução freudiana do eu ou que a substituam por um universo paradigmático melhor. As hipóteses com que se irá trabalhar terão assim muitas conseqüências para a psicanálise porque, ao trabalhar na desconstrução das teorias do eu de Freud, atingem matéria central da psicanálise.

\section{III}

A aproximação entre analítica existencial e psicanálise tem sido feita por grande parte dos autores através de impulsos produzidos por simpatia mútua. É por isso que a maioria das interpretações que, por exemplo, a analítica existencial fez da psicanálise se caracterizam pelas abordagens fragmentárias ou por uma transposição de um universo teórico para dentro de outro universo teórico. É isso que tem acontecido desde Binswanger até a contemporânea psicopatologia fundamental. ${ }^{1} \mathrm{O}$ que se pode observar nisso é que a iniciativa da aproximação sempre partiu de psiquiatras ou psicanalistas, em busca de elementos teóricos ou de instrumentos metodológicos para o estudo do psiquismo humano.

Antes de qualquer aproximação dos dois campos importa distinguir as intenções que conduzem o estudioso da analítica existencial e da psicanálise como tal.

1 Ver, "Regime de constituição de objetos e desconstrução da relaçāo de objetos". Veritas, Porto Alegre, v. 43, n. 1, mar. 1998, p. 109-133. 
Ser e tempo ao analisar a constituição do Dasein, exemplifica-a pelo fenômeno do ser-no-mundo e a apresenta como uma estrutura complexa com muitos aspectos. O Dasein não é monolítico mas também não é um ajuntamento de estruturas. O filósofo afirma a co-originariedade de todas as estruturas, o que significa que a tarefa não consiste em deduzir uma estrutura de outra. A analítica existencial não é uma dedução empírica ou transcendental.

Com isso, no entanto, não estamos condenados a realizarmos uma enumeração rapsódica de aspectos ou elementos que depois deveriam ser combinados numa sinopse. Há, no entanto, em Ser e tempo um momento essencial no parágrafo 40 em que aparece uma estrutura que Heidegger denomina de mais originária. A angústia toma esse lugar privilegiado que leva o autor a utilizar esse existencial como instância particular quando retoma a discussão do ser si mesmo e do $e u$ a que se referira em capítulo anterior. É a angústia que é denominada de afecção fundamental. É na experiência da angústia que o ser-no-mundo é levado à sua singularidade. O autor chega a dizer que "a angústia singulariza o Dasein em direção ao por que ele se angustia e esse enquanto compreensivo se projeta essencialmente em direção de suas possibilidades." 2

A noção ontológica que corresponde ao fenômeno da angústia é o serpossivel de um si (Selbst) singular. É a essa singularização que Heidegger liga o fenômeno da liberdade compreendida como capacidade de se escolher radicalmente a si mesmo. É assim que o filósofo prepara o espaço para a desconstrução do eu na analítica existencial e é assim também que os existenciais passam a ter uma função desestruturante da clássica unidade do eu.

O método de que Heidegger se serve para essa tarefa é a desconstrução hermenêutica. É pela interpretação que a analítica existencial apresenta a inconsistência ontológica do eu e expõe o fenômeno da singularização do Dasein. Portanto, desconstrução como Aus-legung, interpretação, explicitação.

Sigmund Freud na conferência 31 de sua Nova seqüência de conferências introdutórias de psicanálise anuncia a desconstrução do eu como desmontagem (decomposição) da personalidade psiquica "super eu, eu e isso são, portanto, os três âmbitos, regiões, províncias em que desmontamos (Zer-legen) o aparato animico da pessoa."3 A desconstrução que Freud realiza do si (Sebst), do eu, não acontece como interpretação Aus-legung mas como desmontagem Zer-legung.

A atividade analítica que Freud empreende com o ser humano não consiste na apresentação de estruturas complexas co-originárias, nem podemos afirmar que sua teoria analítica consiste numa dedução empírica ou transcendental. Freud realiza simplesmente uma descrição do que comumente se entende por personalidade psíquica, para então praticar a operação de sua desconstrução a partir do desmantelamento de uma unidade imaginária. O resultado dessa desconstruçâo irá consistir na apresentação de âmbitos ou regiões que constituem os componentes essenciais em que se funda a dinâmica dos processos psíquicos do indivíduo.

2 Ver parágrafo 40 Heidegger, Martin. Sein und Zeit, Max Niemeier Verlag, Tübingen, 1977, 14. ed. revista.

3 Freud, Sigmund.. Neue Folge der Vorlesungen zur Einführung in die Psychoanalyse, Gesammelte Werke. London: Imago, 1940, v. 15, p. 79. 
Nessa introdução já se apresentam os paradoxos de duas desconstruções do eu $(I c h)$, e os pressupostos que conduzem o trabalho de desconstrução procedem de origens diferentes. Disso resulta a necessidade de vermos o que é a desconstrução da psicanálise e o que é a desconstrução da analítica existencial. Teremos que nos perguntar qual a relação entre estas duas desconstruções que tratam do mesmo objeto; quais são as conseqüências de uma aproximação da Auslegung da Zerlegung freudiana. No nosso caso aqui iremos desenvolver, primeiro, mais o trabalho de Freud. Isso nos irá preparar o terreno para explorarmos a transposição e aplicação da desconstrução heideggeriana no campo da psicanálise. Naturalmente, o nosso trabalho irá referir-se ou à indicação de falhas de Freud na questão da desconstrução do eu ou de questões mais profundas vindas do seu paradigma filosófico.

\section{IV}

No início da conferência 31 Freud mostra como o ponto de partida é importante na psicanálise e que ela realmente começou a ser ouvida porque se ocupou com o sintoma. Literalmente, Freud diz que o sintoma é o mais estranho ao eu, porque é resultado do recalcado e, ao mesmo tempo, representante desse recalcado diante do eu. Mas o recalcado é para o eu "terra estranha, terra estranha interna, assim como a realidade é terra estranha externa". Do sintoma a psicanálise chegou ao inconsciente e a partir daí à vida pulsional e à sexualidade.

Se Freud agora enfrenta a psicologia do eu e procura uma apresentação que não faça parte da psicologia comum, ele terá que atravessar uma região onde muitas coisas parecem conhecidas e qualquer novidade que ai se queira apresentar pode ser tomada como fantasia. É por isso que ele apela para as estruturas que se manifestam na psicopatologia. Essas estruturas sempre pareceram estranhas para os povos, pois revelavam algo que não era parte do cotidiano.

Assim, o autor inicia a sua analítica do eu pelo caminho psicopatológico. Isso o conduz, através da mania de ser observado, até o problema da consciência para então dizer que o fenômeno que aí aparece pode ser denominado de super eu. Assim está introduzida uma estrutura básica do aparelho anímico. Freud exemplifica isso com a presença do super eu no melancólico, em que a instância do super eu produz efeitos de punição durante períodos e, onde, em outros periodos, o eu parece estar num estado de embriaguez como se o super eu tivesse perdido todas as forças e como que tivesse coincidido com o eu. Esse eu maníaco permite satisfação de todos os seus desejos.

Introduzida, assim, a estrutura do super eu, Freud expõe o processo que o levou ao que ele chama, apoiando-se no uso lingüístico de Nietzsche e por uma sugestão de G. Groddeck, de isso. "Esse pronome impessoal parece particularmente apropriado para expressar o caráter principal dessa província da alma, a saber, sua estranheza diante do eu."4

4 Freud, op. cit., p. 79. 
Com essas três estruturas, super eu, eu e isso Freud apresenta o aparelho anímico que representa a desmontagem da personalidade psíquica. Entretanto, ele observa que, ao lado do super eu, o isso representa a parte obscura inacessivel de nossa personalidade. "O pouco que dele sabemos nós aprendemos pelo estudo do trabalho do sonho e da formação neurótica do sintoma e quase tudo isso tem caráter negativo, podendo ser descrito apenas em oposição ao eu." Freud diz que nos aproximamos do isso através de comparações e "o chamamos de caos ou de caldeira cheio de excitações em ebulição". E continua: "Ligamos isso muito a aspectos somáticos, a necessidades pulsionais que no isso encontram sua expressão psíquica. A partir das pulsões o isso se enche de energia, mas não possui organização, não consegue fazer surgir uma vontade unida, e apenas consegue criar à aspiração de produzir, para as necessidades pulsionais, satisfações, obedecendo ao princípio do prazer." ${ }^{\mathrm{E}} \mathrm{E}$ Freud conclui que para os processos do isso não valem as leis lógicas do pensamento e, particularmente, de modo algum o princípio da não-contradição. Afirma ainda que o isso nada sabe do tempo e nada lembra nele o princípio do filósofo Kant de que nossos atos anímicos possuem como formas necessárias o espaço e o tempo.

O isso é apresentado como aquilo que apenas se liga ao passado, isto é, aparece como recalcado e não constitui a parte menor da ação terapêutica do tratamento analítico.

\section{$\mathrm{V}$}

Introduzidas as três províncias da personalidade psíquica por Freud, através de um modo de proceder específico da lição 31, podemos perguntar pelos caminhos formais que ele esconde na forma de uma apresentação coloquial e um diálogo encenado com um público culto ao qual quer apresentar um novo aspecto da psicanálise que ocupará sua atenção durante muitos anos, mas que ainda não desenvolvera explicitamente.

Se lermos com atenção o texto $A$ desmontagem da personalidade psíquica podemos observar que as oscilações de Freud diante da psicologia do eu já diminuiram consideravelmente. É por isso que ele pode dizer que "minha apresentação da psicologia do eu" vai repercutir no público de maneira muito diferente da "introdução ao mundo psíquico subterrâneo que a precedeu". Freud distingue com especial acento que a psicanálise se tornou até agora conhecida através de fatos, ainda que fossem estranhos e surpreendentes. O que ele agora pretende fazer em 1933 é expor concepções, portanto, na sua expressão, ešpeculações. Sabemos da importância que tiveram as apresentações dos fatos na construção e afirmação da psicanálise. É como se Freud tivesse desconhecido a psicologia do eu e mostrado provocativamente quanto material ela não levara em consideração e que fazia parte agora do mundo psíquico subterrâneo da psicanálise. Freud denomina este mundo de psicologia das neuroses para distinguir o seu conteúdo da psicologia do eu caracterizada por eventos e fatos de uma ordem totalmente diferente dos processos inconscientes.

5 Idem, ibidem, p. 79.

6 Idem, ibidem, p. 80. 
Pode-se perceber que, ao iniciar a Zerlegung, a desmontagem da personalidade psíquica, ele quer, de um lado, garantir uma continuidade das pesquisas que a psicologia do eu fizera, mas que, de outro lado, a psicanálise introduziria uma espécie de ruptura com os fatos aceitos até aí pelos estudos do psiquismo humano. É por isso que nesse texto ele se refere, com diversas expressões, à dificuldade de começar o seu procedimento. O pesquisador se situa diante de diversas possibilidades de abordagens, mas pela constante troca de exemplos e pela variação de novos enfoques de apresentação, o autor dá sinais de que a sua tentativa de desmontagem do eu, por força das exigências dos novos fatos que a psicanálise já pesquisara, apresentava elementos muito novos e, ao mesmo tempo, contudo, necessários para definir a especificidade do material da psicanálise.

É por isso que aí temos de aprender de Freud que é preciso ter um extremo cuidado na avaliação do universo teórico da psicanálise com que ela explicita descobertas na clínica e justifica sua investigação diante do público científico. Temos que reconhecer que o fato de a psicanálise ter partido do sintoma e do recalcamento significou para a psicologia em geral uma absoluta novidade. É por isso que Freud diz: "A partir do sintoma o caminho conduziu para o inconsciente, para a vida pulsional e para a sexualidade,"” provocando reações de estranhamento e críticas violentas.

Querer agora apresentar estruturas que sustentam toda essa realidade dinâmica da psicanálise representava uma empresa difícil de ser iniciada, ainda mais difícil de ser justificada e, acima de tudo, correndo o risco de se desfazer em meras especulações. Podemos dizer que a psicanálise conseguiu justificar a dinâmica do psiquismo humano como um todo, mas permaneceu um projeto não acabado no que se refere à construção das estruturas sobre as quais essa dinâmica se apóia. É por essa razão que a metapsicologia de Freud desperta a suspeita de grande fragilidade e de que se constitui por um conjunto de categorias que poderiam ser melhoradas ou mesmo substituídas. É a razão por que muitos teóricos tentaram apresentar novas propostas para a metapsicologia freudiana, como, por exemplo, Binswanger, Lacan, Winnicott e outros.

Freud sabia muito bem da radicalidade de suas intuições com relação à dinâmica do psiquismo humano, sobretudo inconsciente, e para essa dinâmica ele encontrou um universo categorial preciso e metáforas e analogias que entraram na cultura ocidental. Entretanto, ao falar das estruturas do edifício teórico, a sua obra ficou incompleta por duas razões. De um lado, ele não queria apresentar um edificio psicológico totalmente novo e, de outro lado, porque ele sabia da necessidade de não poder utilizar simplesmente as categorias da psicologia sem submetê-las a uma desconstrução, decomposição em sua linguagem.

Assim nos encontramos com Freud, quando trata da psicologia do eu, num terreno favorável a um diálogo, a procedimentos semelhantes aos de Freud e até a sugestões para substituir categorias da psicanálise no que se refere à estrutura do psiquismo humano e da relação do homem consigo, com o mundo e com os outros. Chegamos assim à possibilidade de nos juntarmos a Freud para pensarmos com categorias contemporâneas aquilo que ele tentara na metapsicologia e com-

7 Freud, op. cit., p. 62. 
pletarmos aspectos que concepções filosóficas atuais sobre o ser humano apresentam de maneira mais convincente e produtiva, testando outros universos paradigmáticos na produção de conceitos.

No entanto, é preciso tomar como advertência o risco de, ao trabalhar com Freud, desconstruirmos elementos de sua metapsicologia, atentando contra a intuição fundamental que é a matriz da psicanálise: o retorno do recalcado como sintoma. Dito de muitos modos, esse teorema não pode ser tocado, pois sem ele de nada valeria a melhor reconstrução do edifício metapsicológico.

\section{VI}

Quando Freud inicia o desmantelamento da categoria do eu da psicologia, ele não realiza simplesmente uma correção. Temos a impressão, ao ler a lição 31 , que estamos na presença de alguém escolado na clínica, esclarecido pela casuística e confirmado nos debates em torno dos eventos e dos fatos do inconsciente, mas que tem receio de erigir um edifício metapsicológico apenas com a crítica dos conceitos da psicologia. Freud aparece aqui como pesquisador, como teórico da constituição do ser humano e como analista e intérprete de um mundo categorial novo. Ele se pergunta: como deve ser constituído um ser que se rege pela dinâmica do inconsciente em suas estruturas essenciais de caráter psicológico, psicopatológico e existencial? Acompanhando Freud nessa pergunta estaremos no caminho que ele seguiu e que nós teremos que seguir.

Ainda que Freud não tenha inventado o termo eu, nem mesmo as expressões inconsciente e consciente, a maneira como recebeu as teorias referentes a esses universos temáticos estão na raiz da psicanálise. Vindo da tradição alemã, a questão do eu era apresentada por Freud, poderíamos dizer, fora da sua pretensão de fundar um novo conhecimento, bem ao modo das análises dos grandes filósofos alemães desde o século XIX: "O eu é o mais próprio do sujeito, como pode ele ser convertido em objeto? Entretanto, não há dúvida de que podemos isso. $\mathrm{O}$ eu pode tomar a si mesmo como objeto, tratar-se como outros objetos, observar-se, criticar-se e sabe Deus quanta outra coisa a gente pode fazer consigo mesmo. Nisso uma parte do eu se coloca em face do resto do eu. O eu é, portanto, passivo de ser cindido, cinde-se durante muitas de suas funções, ao menos passageiramente. As partes constituintes podem depois novamente ser reunidas." 8 Esta passagem da conferência 31 parece uma descrição de Fichte ou de Hegel.

Apresentada com certa ironia, reproduz as convicções da filosofia do idealismo alemão. Mas, ao mesmo tempo, o que era pensamento generalizado na tradição antropológica, psicológica e ética correntes, Freud já aprendera em 1883 com seu professor Meynert que o eu se dividia entre um eu primário e um eu secundário. Mas essas distinções psiquiátricas interessavam-no não como pano de fundo filosófico para concepções organicistas (mesmerianas) do funcionamento do espírito humano. Muito cedo a prática o pusera em contato com diferentes afecções psíquicas como a histeria, as idéias obsessivas, as confusões alucinatórias e a paranóia. Tanto na sua correspondência com Fliess, como o seu Esboço de uma

8 Freud, op. cit., p. 64. 
psicologia científica, revelam sua concentração sobre a natureza das relações conflitivas do eu. É por isso que, já no capitulo VII da Interpretação dos sonhos, se esboça a primeira tópica com a qual pretendia descrever a estrutura que sustentava os conflitos. Sua obra Três ensaios sobre a teoria sexual termina explicitando o eu como o lugar de um sistema pulsional onde se diferenciam as pulsões sexuais através de um apoio no eu. Ainda que apresentadas como completamente distintas são decisivas para o quadro em que se constitui o eu como sede de um investimento libidinal, ao lado da libido de objeto.

São diversas as etapas teóricas que levam até a segunda tópica dos anos 20 que vai se confirmando no ensaio $\mathrm{O}$ eu e $\mathrm{O}$ isso, até chegarmos à lição 31 em que Freud fala da consciência como o "único farol que nos ilumina na psicologia profunda" (afirmação semelhante aparecerá novamente em 1938) e conclui com a celebrada expressäo: Wo es war soll ich werden. ${ }^{9}$

Essa expressão que liga isso e eu fará surgir, conforme a natureza que se atribuir a essa ligação, as principais leituras divergentes da doutrina freudiana: a) a Ego psychology de Anna Freud que verá no eu um pólo de defesa ou de adaptação à realidade; b) a vertente lacaniana, em que o eu imerge no isso e é cindido num moi e num je; c) e a Self psychology em que o eu é inserido numa fenomenologia do si ou da relação de objeto. Podemos afirmar que nenhuma das três vertentes permanece fiel ao Freud da lição sobre $A$ decomposição da personalidade psíquica. Wo es war soll ich werden Freud formula um novo imperativo para a cultura que Freud compara ao secamento por etapas do Zuiderzee.

\section{VII}

A desmontagem da personalidade psíquica que representa uma síntese da doutrina de Freud com relação ao eu, onde sobram poucas interrogações, constitui o ponto mais avançado de que foi capaz de desenvolver o pesquisador Freud. Aquele que pergunta pela constituição do ser em que acontece a dinâmica de que se ocupa a psicanálise e procura estabelecer as condições de possibilidade ou as estruturas que the permitam pensar numa unidade, a dinâmica, a tópica e à econômica. Preocupado na elaboração de modelos teóricos não ligados diretamente à pratica e à observação clínica, procura dar conta nos diversos ensaios de sua metapsicologia da compreensão científica que explica a dinâmica, a tópica e a econômica. No seu artigo sobre o inconsciente, Freud define a metapsicologia da seguinte maneira: "Eu proponho falar de apresentação metapsicológica quando somos bem sucedidos em descrever um processo psíquico sob os pontos de vista dinâmico, tópico e econômico. Posso prever no estado atual de nossos conhecimentos que não alcançaremos a não ser pontos isolados."10

Em Para além do princípio do prazer, Freud fala ainda mais fortemente dos três elementos teóricos citados: "Nós pensamos que um modo de exposição onde se tenta apreciar o fator econômico, além dos fatores tópico e dinâmico, é o mais completo que nós poderíamos nos representar atualmente e que ele merece ser posto em evidência pelo termo de metapsicológico." 11

9 Freud, op. cit., p. 86

10 Idem, ibidem, p. 61.

11 Freud, Sigmund. Jenseits des Lustprinzips - Gesammelte Werke. London: Imago, v. 13, p. 3. 
Estas duas passagens são suficientes para mostrar o quanto é importante passar a ver a relevância da metapsicologia na questão do eu para Freud.

Para situar a complexidade da posição de Freud diante de sua atividade ocupada com a metapsicologia é necessário manter abertas várias direções de seu pensamento. Metapsicologia significa para Freud um termo teórico para se distinguir da psicologia do eu, mas de outro lado, pretende apresentar-se como uma psicologia das neuroses e por fim uma continuação ou passagem da medicina para uma psicologia nova, a psicanálise. Mas, enquanto ela se ocupa com o conhecimento de fatos psíquicos do inconsciente, a metapsicologia se transforma em "construção de uma realidade supra-sensível que a ciência transforma numa psicologia do inconsciente” (Psicopatologia...). A metapsicologia é que levará Freud a colocar o problema do eu ligado ao universo da biologia, com conseqüências pesadas.

A intenção do autor em manter abertas todas estas direções é se apossar de conhecimentos teóricos e realizar uma empresa intelectual que tome uma "forma científica" que "toma de empréstimo seu objeto da démarche filosófica". Somente assim ela levará a pensar a articulação possivel de processos psíquicos com os fundamentos biológicos. Escrevendo a Fliess em 1898 Freud falando dos sonhos diz: "Parece-me que a explicação pela realização de um desejo dá, certamente, uma solução psicológica, mas não uma solução biológica, muito antes uma metapsicológica." E acrescenta: "Aliás, importa que me digas seriamente se eu posso dar à minha psicologia, que irrompe pelas costas no consciente, o nome de metapsicologia."

Em Psicopatologia da vida cotidiana Freud diz que a metafísica pode até constituir uma espécie de modelo formal para a metapsicologia a ser pensada; seu objetivo, no entanto, não consiste em se fechar nisso, mas de avaliá-la e estabelecer que as construções filosóficas (mitológicas e religiosas), com o mesmo direito que todas as formas de crenças e delírios que dela podem derivar, não constituem outra coisa que "uma psicologia projetada no mundo exterior". Freud tira uma conclusão importante diante dessa conseqüência, dessa psicologia querendo ser filosofia. "Poderíamos dar-nos como tarefa decompor (Zerlegen), colocando-se nesse ponto de vista os mitos relativos ao paraíso e ao pecado original, ao mal e ao bem, à imortalidade, etc. e traduzir a metafísica em metapsicologia."12 As duas citações sobre dinâmica, tópica e econômica que citamos acima e que tratavam do inconsciente e da questão do além do princípio do prazer, tratam esses dois aspectos metapsicologicamente. Nesse contexto é que o autor situa diversos ensaios desde o Esboço da psicologia, passando pelo capítulo VII da Interpretação dos sonhos, pelo texto Para introduzir o narcisismo, pelo Eu e o Isso e pelo Essboço de psicanálise no fim dos anos 30 .

Mas o uso que Freud faz da expressão metapsicologia recebe um outro sentido quando redige os Elementos para uma metapsicologia por volta de 1915 ao redigir os 12 ensaios dos quais nos sobraram Pulsões e destino das pulsões, 0

12 Idem, ibidem, p. 15. 
recalcamento, 0 inconsciente, Complemento metapsicológico da doutrina dos sonhos, Luto e melancolia e um sexto texto descoberto recentemente Visão geral das neuroses de transferência. ${ }^{13}$

O primeiro sentido de metapsicologia é estabelecido por Freud com a intenção de impedir, através de uma espécie de barreira epistemológica, as derivações psicologistas e organicistas que ameaçavam a psicanálise. O segundo sentido de metapsicologia que está implícita nos doze ensaios traz uma nova idéia de Freud que rompe com o primeiro projeto metapsicológico e pretende ser uma construção sistemática em que já se articula aquilo para o qual encontramos documentos em toda obra de Freud: a vinculação da perspectiva ontogenética com a aventura da reconstituição filogenética tentada nos 12 ensaios.

Esses dois sentidos de metapsicologia, ao mesmo tempo em que o primeiro pretende ser uma defesa contra o biologismo e o segundo uma inserção num processo biológico, se encontram no objetivo de Freud de desenvolver uma teoria da articulação do psiquismo com o substrato biológico. Era, no entanto, importante que se garantisse um discurso da psicanálise claramente separado da psicologia e do modo como ela desembocaria no biológico e que, de outro lado, abrisse um caminho para que todo o edifício da psicanálise se orientasse para um dia poder se desfazer, inserindo-se nas futuras descobertas da biologia. Era importante para Freud que não se resolvessem os problemas psicológicos numa explicação biológica adequada à psicologia, mas que os processos dinâmicos da psicanálise, com suas inovações teóricas e clínicas, encontrassem uma explicação biológica própria. Freud queria impedir que as teorias da psicologia e as teorias da psicanálise caíssem numa vala biológica comum. Para ele é muito diferente o edifício da psicologia terminar num experimentalismo biológico, que o edifício psicanalítico, enquanto construção metapsicológica pioneira e teoria antecipadora, se dissolver nas conquistas da biologia. No caso da psicologia, estar-se-ia dando uma solução simplista e como diz Freud, "projetada no mundo exterior", enquanto que no caso da psicanálise haveria uma espécie de substituição, mas também de continuidade, da explicação dinâmica dos processos psíquicos. No fundo, para Freud, a ligação entre psicologia e biologia é radicalmente diferente do vínculo entre psicanálise e biologia.

\section{VIII}

O que é afirmado no Wo es war soll ich werden terminou sendo o mote do fim do trabalho da desmontagem da personalidade psíquica ou do eu, assinalando uma tarefa inacabável como a secagem do Zuiderzee. Mas a tarefa descrita no fim da conferência 31 é direcionada por Freud para o fortalecimento do eu. Os "esforços terapêuticos da psicanálise" têm a "intenção de fortalecer o eu, torná-lo mais independente, super eu, ampliar seu campo de percepção e construir sua organização de maneira tal que possa se apropriar de novos fragmentos do isso." 14

13 Ver Freud, Sigmund. Ubersicht der Übertragunsneurosen Ein bisher unberkanntes Manuskript, o Darmstadt, 1985.

14 Freud, op. cit., p. 86. 
recalcamento, $O$ inconsciente, Complemento metapsicológico da doutrina dos sonhos, Luto e melancolia e um sexto texto descoberto recentemente Visão geral das neuroses de transferência. ${ }^{13}$

O primeiro sentido de metapsicologia é estabelecido por Freud com a intenção de impedir, através de uma espécie de barreira epistemológica, as derivações psicologistas e organicistas que ameaçavam a psicanálise. O segundo sentido de metapsicologia que está implícita nos doze ensaios traz uma nova idéia de Freud que rompe com o primeiro projeto metapsicológico e pretende ser uma construção sistemática em que já se articula aquilo para o qual encontramos documentos em toda obra de Freud: a vinculação da perspectiva ontogenética com a aventura da reconstituição filogenética tentada nos 12 ensaios.

Esses dois sentidos de metapsicologia, ao mesmo tempo em que o primeiro pretende ser uma defesa contra o biologismo e o segundo uma inserção num processo biológico, se encontram no objetivo de Freud de desenvolver uma teoria da articulação do psiquismo com o substrato biológico. Era, no entanto, importante que se garantisse um discurso da psicanálise claramente separado da psicologia e do modo como ela desembocaria no biológico e que, de outro lado, abrisse um caminho para que todo o edifício da psicanálise se orientasse para um dia poder se desfazer, inserindo-se nas futuras descobertas da biologia. Era importante para Freud que não se resolvessem os problemas psicológicos numa explicação biológica adequada à psicologia, mas que os processos dinâmicos da psicanálise, com suas inovações teóricas e clínicas, encontrassem uma explicação biológica própria. Freud queria impedir que as teorias da psicologia e as teorias da psicanálise caíssem numa vala biológica comum. Para ele é muito diferente o edifício da psicologia terminar num experimentalismo biológico, que o edifício psicanalítico, enquanto construção metapsicológica pioneira e teoria antecipadora, se dissolver nas conquistas da biologia. No caso da psicologia, estar-se-ia dando uma solução simplista e como diz Freud, "projetada no mundo exterior", enquanto que no caso da psicanálise haveria uma espécie de substituição, mas também de continuidade, da explicação dinâmica dos processos psíquicos. No fundo, para Freud, a ligação entre psicologia e biologia é radicalmente diferente do vínculo entre psicanálise e biologia.

\section{VIII}

O que é afirmado no Wo es war soll ich werden terminou sendo o mote do fim do trabalho da desmontagem da personalidade psíquica ou do eu, assinalando uma tarefa inacabável como a secagem do Zuiderzee. Mas a tarefa descrita no fim da conferência 31 é direcionada por Freud para o fortalecimento do eu. Os "esforços terapêuticos da psicanálise" têm a "intenção de fortalecer o eu, torná-lo mais independente, super eu, ampliar seu campo de percepção e construir sua organização de maneira tal que possa se apropriar de novos fragmentos do isso." 14

13 Ver Freud, Sigmund. Übersicht der Übertragunsneurosen Ein bisher unberkanntes Manuskript, o Darmstadt, 1985.

14 Freud, op. cit., p. 86. 
Ainda que seja definido como uma das províncias da alma o eu é posto ao final da Zerlegung, da desmontagem como enfrentando três senhores coercitivos: 0 mundo exterior, o super eu e o isso. "Se acompanhamos os esforços do eu em agradar simultaneamente aos três, não teremos direito ao arrependimento por termos personificado esse eu, de tê-lo estabelecido como um ser singular que se sente encurralado por três lados, ameaçado por três tipos de perigos diante dos quais reage com angústia."15

A metapsicologia freudiana aparece neste contexto cindida em duas tendências. Do ponto de vista clínico e da teoria do sintoma ela propõe um acordo entre o eu e o retorno do recalcado estabelecendo uma relação conflitiva interminável. É a partir dessa visão de conflito entre o eu e o isso que Freud falará de análise finita e infinita.

O eu está doente, enfraquecido mas possui ainda uma posição privilegiada. Esta é a posição de Freud, ainda que na conferência 31 admita um poder decisivo do isso diante do eu, na analogia que o autor faz do cavaleiro e do cavalo. Mas, como conclusão, a desmontagem, a Zerlegung, preserva uma dimensão mais sólida para o eu diante das outras instâncias do aparelho psíquico.

Há, no entanto, uma outra direção da metapsicologia que se apresenta através de um certo paralelismo entre o ontogenético e o filogenético. Esta posição é explorada através do grandioso panorama traçado nos doze ensaios sobre as neuroses de transferência. Nelas se revela o lado implosivo do eu na questão do narcisismo. Comparada com os investimentos de objeto a libido do eu é entrópica.

Mas, mesmo com as novas descobertas em Para além do princípio do prazer, da compulsão sem ganho e das pulsões de vida e de morte, Freud estabelece a nova tópica com a incorporação do isso (ES), expressão criada por Goddeck em 1923, o eu continua privilegiado em todas as teorias que Freud desenvolve.

Podemos observar aqui a solidez de um paradigma filosófico que ainda se preserva e com ele a concepção do eu que nele está enraizado. As teorias do eu e da subjetividade sustentam-se mesmo diante de evidências cada vez mais fortes de que a simples desmontagem do eu (Zerlegung) não consegue atingir o problema central. Seria simplesmente por falta de radicalidade na exposição do lugar do eu na tópica?

É verdade que Freud termina admitindo a crise do eu e a insustentabilidade do lugar que ocupava na metafísica da modernidade, quando, compelido pela teoria do narcisismo e das descobertas de Para além do princípio do prazer, introduz a pulsão de morte. Nesse sentido a questão do eu é resolvida com o seu pleno desaparecimento. O fundador da psicanálise confessa dessa maneira que pensa que a teoria do eu é o anteparo erguido diante da morte e da finitude. Mas esta idéia lhe é insuportável, tanto assim que a questão do narcisismo desaparece no último Esboço de psicanálise de 1938.

Sem nos mostrarmos afoitos demais podemos dizer que as conseqüências da segunda tendência da metapsicologia, que põe em xeque o eu, não se esclarecem a não ser que seja desconstruído o paradigma metafísico em que ela tomou forma.

15 Idem, ibidem, p. 84. 
As conseqüências da metapsicologia freudiana presa ao paradigma metafísico conduz o fundador da psicanálise, não a rejeitar a sua construção teórica, mas a afirmar que um dia ela será substituída pelas descobertas da biologia, o universo físico-químico. É por isso que Freud confessa desde 1895 a explicação naturalística dos fenômenos psíquicos.

Muito informativas são para isso as seguintes passagens da obra de Freud:

1) "Oue todas as nossas propriedades psicológicas sejam um dia fundadas no chão de suportes orgânicos" (Introdução ao narcisismo, 1914).

2) "O edifício doutrinário da psicanálise que construímos é na realidade uma superestrutura que um dia deverá ser assentada sobre seu fundamento orgânico; mas nós ainda não o conhecemos" (Conferências introdutórias à psicanálise, 24, 1917).

3) "Se nos fosse possível pela via química intervir nesta engrenagem, aumentar ou diminuir a quantidade de libido presente em cada situação ou fortalecer uma pulsão à custa de outra, isso seria então, em sentido próprio, uma terapia causal" (Conferências introdutórias à psicanálise, 27, 1917).

4) "As falhas na descrição provavelmente desapareceriam se em lugar dos termos psicológicos já pudéssemos usar os fisiológicos ou químicos" (Para além do princípio do prazer, 1920.

5) "A determinação de todas as nossas análises que denominamos metapsicológicas procede obviamente do fato de não sabermos nada sobre a natureza dos processos de excitação dos elementos psíquicos e de não nos sentirmos no direito de aceitar resposta alguma. Portanto, operamos assim constantemente com um grande $\mathrm{X}$ o qual levamos junto para dentro de cada fórmula nova" (Para além do principio do prazer, 1920).

6) "O elemento psíquico, seja ele de que natureza for, é inconscientemente de espécie similar a todos os outros processos da natureza dos quais tomamos conhecimento" (Esboço de psicanálise, 1938).

Ao lermos essas passagens podemos perguntar-nos o que restaria propriamente da realidade do eu que enfrenta o mundo exterior, o isso e o super eu, se toda a construção metapsicológica é realmente apenas provisória para Freud, esperando ele a dissolução de todos os processos psíquicos em reações químicas. Seria uma conseqüência do caráter metafísico da construção metapsicológica do eu o fato de Freud terminar por dissolvê-lo na biologia?

O trabalho que o fundador da psicanálise apresenta na conferência 31 sobre a desmontagem da personalidade psíquica - a Zerlegung - não chega a satisfazer as exigências da desconstrução do paradigma em que se apóia. O mesmo acontece com a tentativa de explicar radicalmente os fenômenos da clínica, o sintoma como retorno do recalcado e a questão da transferência?

Precisamos pensar nas estruturas de que se utilizou a metapsicologia freudiana. Estas não foram explicitadas. Ao menos não são suficientes para dar conta da combinatória do aparelho psíquico na produção de sua econômica e dinâmica. Freud diante dos problemas que restam da Zerlegung escolheu para o eu a pulsão de morte, a submersão no inorgânico ou no mundo da biologia. 
Quando, então, formos pensar não mais no paradigma da Zerlegung, mas da Auslegung, abrimos um novo caminho para a desconstrução da metapsicologia freudiana que nos deixou, após tantas vicissitudes, a questão do eu para ser pensada a partir de estruturas que não nos levem a dissolvê-lo no mundo da biologia. A desconstrução analítico-existencial ou hermenêutica não pretende substituir a clínica freudiana, nem o princípio fundador da psicanálise de que o recalcado retorna como sintoma. Talvez a desconstrução hermenêutica possua outros instrumentos que se articulam num outro paradigma para mostrar a verdadeira origem da metapsicologia freudiana. A investigação mostrará o que falta na Zerlegung. Na medida em que concebe o eu e os destinos do eu no quadro da metafisica, terá a Auslegung novas possibilidades para pensar essas questões? 